\title{
DESENVOLVIMENTO DE UM GUIA DE REPAROS PARA DIFERENTES TIPOS DE PATOLOGIA RELATIVOS À UMIDADE NAS EDIFICAÇÕES
}

\author{
J. Neves ${ }^{1}$, D. Garcia ${ }^{2 *}$, V.Santana ${ }^{1}$, C. Lopes ${ }^{3}$, J. Mendes ${ }^{1}$ \\ *Autor de Contato: danielle.garcia@engenharia.ufjf.br \\ ${ }^{1}$ Departamento de Engenharia Civil, Escola de Minas, Universidade Federal de Ouro Pedro, Ouro Preto, Brasil \\ ${ }^{2}$ Departamento de Engenharia Civil, Faculdade de Engenharia, Universidade Federal de Juiz de Fora, Juiz de Fora, \\ Brasil \\ ${ }^{3}$ Engenheira Civil, Técnica do Instituto Brasileiro de Geografia e Estatística, Ouro Preto, Brasil
}

\begin{abstract}
RESUMO
O presente trabalho objetiva investigar e analisar criticamente as principais causas de patologia relacionadas à umidade em edificações brasileiras e auxiliar os usuários destas a solucioná-las. A metodologia adotada foi revisão bibliográfica dos principais danos causados pela umidade, a partir da qual foram selecionados métodos práticos para repará-los, visando atender o público leigo. Como resultado, foi desenvolvido um material prático e didático, visando guiar a população em relação às melhores formas de se detectar e reparar a patologia gerada pela umidade existentes em suas edificações. O guia foi baseado em grandes fornecedores brasileiros e uniu diversos reparos causados por umidade em um só documento. Espera-se, com esse guia, auxiliar a população a melhorar o desempenho e habitabilidade das suas residências.
\end{abstract}

Palavras-chaves: Patologia; Umidade; Infiltração; Reparos.

\section{RESUMEN}


El presente trabajo tiene como objetivo investigar y analizar críticamente las principales causas de patología relacionada con la humedad en edificios brasileños y ayudar a los usuarios a resolverlas. La metodología adoptada fue una revisión bibliográfica de los principales daños ocasionados por la humedad, a partir de la cual se seleccionaron métodos prácticos para repararlos, con el objetivo de servir al público lego. Como resultado, se desarrolló un material práctico y didáctico, con el objetivo de orientar a la población en relación a las mejores formas de detectar y reparar la patología generada por la humedad existente en sus edificios. La guía se basó en grandes proveedores brasileños y combinó varias reparaciones causadas por la humedad en un solo documento. Se espera que esta guía ayude a la población a mejorar el rendimiento y habitabilidad de sus viviendas.

Palabras clave: Patología; Humedad; Infiltración; Refacción.

\begin{abstract}
The present work aims to investigate and critically analyze the main causes of pathology related to humidity in Brazilian buildings and help users to solve them. The methodology adopted was a bibliographic review of the main damages caused by moisture, from which practical methods were selected to repair them, aiming to serve the lay public. As a result, a practical and didactic material was developed, aiming to guide the population in relation to the best ways to detect and repair the pathology generated by the humidity existing in their buildings. The guide was based on major Brazilian suppliers and combined several repairs caused by moisture in a single document. It is hoped that this guide will help the population to improve the performance and habitability of their homes.
\end{abstract}

Keywords: Pathology; Humidity; Infiltration; Repairs. 


\section{INTRODUÇÃO}

Nas últimas décadas, a construção civil tem apresentado um considerável crescimento, revelandose um mercado extremamente competitivo. Com isso, a redução desmedida dos prazos e custos se tornou o foco do construtor, desde o planejamento até a execução e a entrega da obra. Com esses fatores, tornou-se visível um problema que até então se escondia: o baixo nível de qualidade e de produtividade na construção civil brasileira (Garrafoli, 2010).

O Brasil possui a Norma de Desempenho, a NBR 15575 (ABNT, 2013), e o Programa Brasileiro da Qualidade e Produtividade do Habitat (PBQP-H), que têm como objetivo organizar o setor da construção civil através da melhoria da qualidade das construções habitacionais e da modernização produtiva. Entretanto, além da padronização e atualização das normas, é necessário que haja fiscalização, garantindo que as mesmas sejam seguidas. Além disso, predomina a autoconstrução no país. A informalidade do setor da construção civil chega a $60 \%$, o que se relaciona com a ausência pela busca por conhecimento e cumprimento das normas por parte dos profissionais dessa indústria (Martins, 2019).

Os sistemas e elementos construtivos necessitam de atividades de manutenção ao longo de sua vida útil para garantir níveis aceitáveis de desempenho e de segurança. Culturalmente, no Brasil, a manutenção de imóveis é negligenciada, seja por esquecimento, ignorância ou razões econômicas, gerando incalculáveis problemas que se manifestam de médio a longo prazo (Nakamura, 2018).

A informalidade e ausência da cultura de manutenções no setor da construção também prejudica a concepção e execução de projetos. No mercado brasileiro há uma deficiência e às vezes até inexistência de projetos de impermeabilização das edificações, o que acarreta o aparecimento de patologia devido à umidade. Normalmente, quando essa patologia é corrigida, observa-se a execução de métodos paliativos e sem o acompanhamento de um responsável técnico habilitado. A umidade é a manifestação patológica mais frequentemente observada nas edificações (Perez, 1985). Entre a patologia ligada à ação da água na edificação, podemos citar aquelas causadas por umidade por capilaridade, umidade por condensação, umidade acidental, umidade por infiltração (França, Marcondes, et al., 2011). De acordo com Verçosa (1991), a presença de umidade não é apenas uma patologia em si, mas ainda acentua ou acarreta a ocorrência de um grande número de outras manifestações patológicas. É por meio dela que surgem eflorescências, ferrugens, mofo, bolores, perda de pinturas, desplacamento de rebocos e até acidentes estruturais (Bauermann, 2018). Os problemas mais comuns decorrentes da penetração de água podem ser: prejuízos de caráter funcional da edificação; desconforto dos usuários; deterioração da saúde dos moradores (em casos extremos); danos em equipamentos e bens presentes nos interiores das edificações e prejuízos financeiros (Souza, 2008).

Segundo Ripper e Souza (1998), algumas das causas da patologia ligada à umidade são: falhas nas concepções do projeto (como falta de compatibilização entre os projetos, especificação inadequada dos materiais e detalhamento insuficiente ou errado); falhas humanas durante a execução, devido à deficiência de qualificação profissional e/ou fiscalização; utilização errônea da edificação; ausência de um programa de manutenção adequado; inexistência de controle de qualidade dos materiais e a inadequação ao ambiente, deixando a estrutura exposta à ação da água (como quando há falta de um sistema de impermeabilização). A autoconstrução só agrava essa situação, uma vez que a ausência de projetos formais e de um engenheiro fiscal de execução aumenta a probabilidade de estas negligências ocorrerem.

Dessa forma, o propósito do presente trabalho é auxiliar a população que sofre com os problemas gerados pela umidade em edificações brasileiras, trazendo uma revisão bibliográfica das principais causas de patologia ocasionadas pela umidade e oferecendo um material que as guie da melhor forma a detectar e solucionar a patologia desse tipo já existentes em suas edificações. Além disso, 
foi feita uma análise crítica das principais causas da proliferação dessas manifestações patológicas nas residências brasileiras.

\section{METODOLOGIA}

O método de pesquisa utilizado é o descritivo, no qual foi usada a técnica de análise de dados. Inicialmente, foi realizada uma revisão das características e causas dos principais tipos de patologia causadas por umidade nas edificações, por meio de autores de referência na literatura. Para a realização do guia de reparos de patologia de umidades em edificações foi realizada uma extensa pesquisa bibliográfica e foram selecionados os métodos mais práticos para reparar os danos causados pela umidade. Para isso, foram analisadas especificações de grandes fabricantes.

Como o objetivo é que o Guia de Reparos fosse de fato algo realizável pela população, foram analisadas marcas com representatividade no mercado e de fácil acesso no Brasil. Porém, cada produto citado pode ser substituído por outro com a mesma funcionalidade.

Para a produção do Guia de Reparos foram utilizados como referências os manuais de instruções desses grandes fabricantes. Além dos manuais técnicos, o principal autor que contribuiu foi o Yazigi (2009) do livro “A Técnica de Edificar", que apesar de seu foco ser na construção e não no reparo, colaborou para o entendimento dos processos a serem feitos.

\section{RESULTADOS}

\subsection{Revisão bibliográfica dos principais tipos de patologia de umidade \\ 3.1.1 Umidade ascendente}

Entende-se por capilaridade o fenômeno de subida da água através de canais extremamente finos presentes nas estruturas dos materiais de construção (Rendelucci, 2005). Assim, essa umidade é proveniente da absorção da água presente no solo, que pode ser água superficial ou do lençol freático, pelas paredes e/ou piso.

A identificação desta patologia é feita visualmente e sua manifestação pode ser observada a até um metro de altura nas paredes (Figura 1) (Kauffeman, 2017). Os sintomas podem ser bolhas, manchas escuras próximas ao piso, manchas brancas devido à eflorescência e descolamento de rebocos e materiais de revestimento (Souza, 2008).

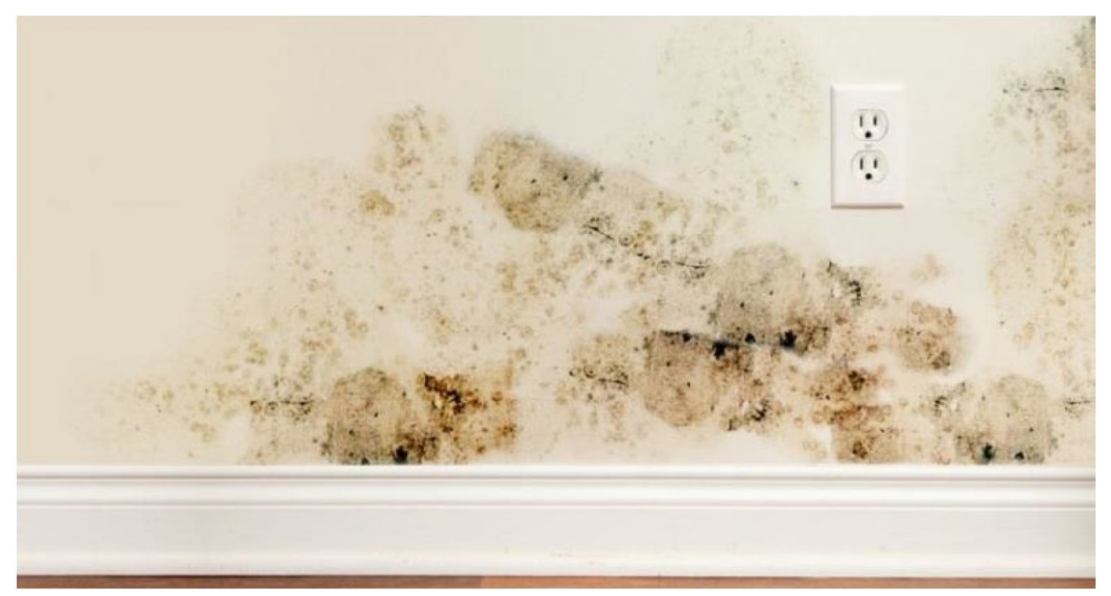

Figura 1. Parede com o surgimento de manchas escuras, como mofo, que podem indicar a presença de microrganismos danosos à saúde (Brucke, 2018). 


\subsubsection{Umidade por condensação}

A umidade nas edificações não é originada apenas da infiltração de água externa. Também pode ser proveniente do vapor de água que condensa em superfícies mais frias, como paredes internas, teto, vidros e estruturas metálicas (Tintas e Pintura, 2017). Geralmente essa patologia se manifesta em locais mais frios e úmidos e em cômodos com deficiência de ventilação (Kauffeman, 2017). Em climas tropicais, é possível identificar com maior frequência a ocorrência da umidade por condensação no teto de banheiros, devido ao vapor liberado pelos banhos quentes (Figura 2). A identificação desta patologia é visual, tem-se o aparecimento de manchas escuras e destacamento da pintura e até formação de gotas (Oliveira, 2017).
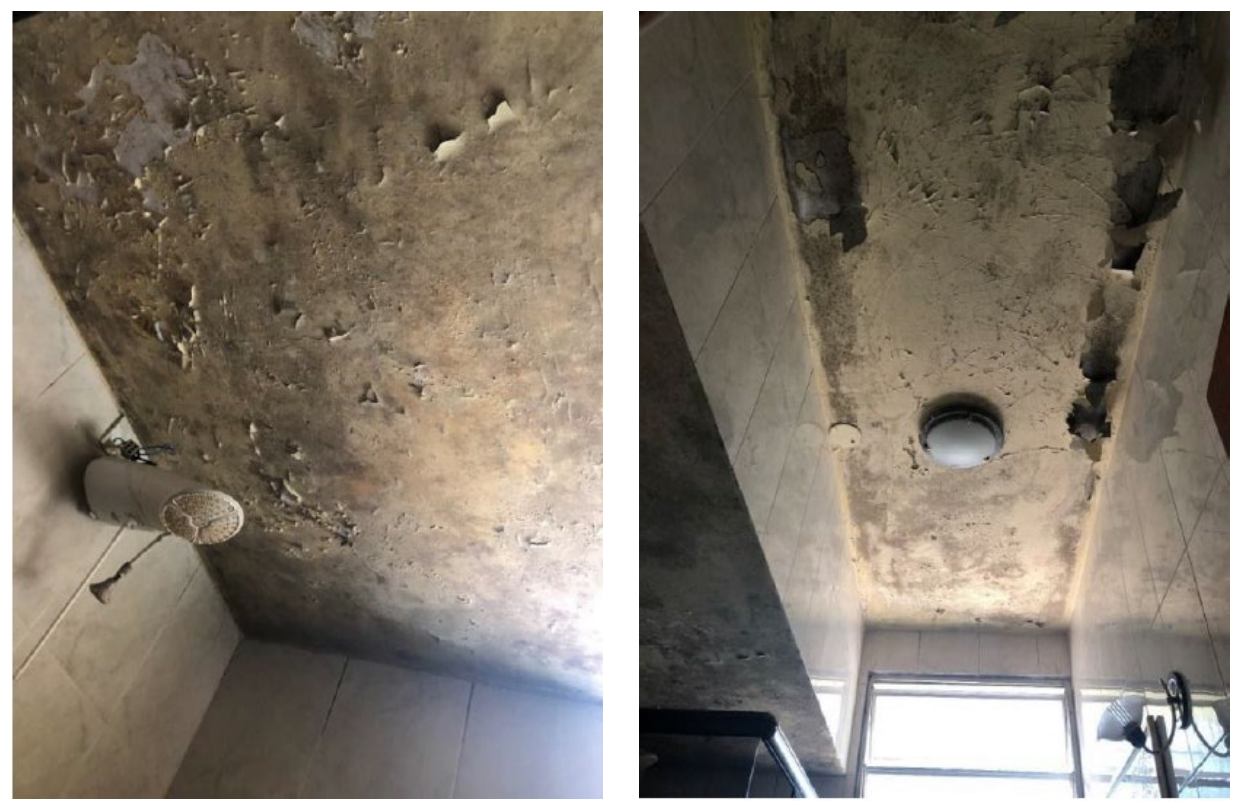

Figura 2. Surgimento de mofo e destacamento da pintura devido ao intenso contato com o vapor quente com a superfície fria do teto, localizado em uma residência em Ouro Preto, MG (Fonte:

Autora).

\subsubsection{Umidade acidental}

Esta forma de manifestação de umidade está associada às fugas de água provocadas por defeitos de construção ou de funcionamento de determinados equipamentos e/ou instalações de águas pluviais, esgoto e água potável (Santos, Ribeiro, et al., 2012/2013). Esta patologia pode surgir seja por falha na execução do sistema hidrossanitário, falta de impermeabilização de lajes, falhas na cobertura, erros de dimensionamento das calhas, calhas entupidas por folhas, furos e vazamento de tubulações e até mesmo algum acidente, por exemplo, quando se atinge a tubulação de água ao furar uma parede (Kauffeman, 2017). Por essas e outras razões, é importante que o usuário tenha conhecimento do projeto hidráulico. Quando se trata de edificações que já possuam um longo tempo de existência, pode haver presença de materiais e sistemas com período de vida útil já excedido, que não costumam receber manutenção predial adequada, se tornando um cenário fácil para o aparecimento desta patologia (Santos, Ribeiro, et al., 2012/2013).

\subsubsection{Vazamento de redes de água e esgoto}

Segundo Verçoza (1991), os vazamentos de redes de água e esgoto são de difícil localização e correção. Isso se deve ao fato destes vazamentos estarem na maioria das vezes encobertos pelo revestimento. A Figura 3 ilustra um vazamento decorrente de defeito no encanamento, gerando 
uma infiltração por uma grande extensão da parede. Além de problemas estéticos e consequências nos demais sistemas da edificação, há desperdício de água.

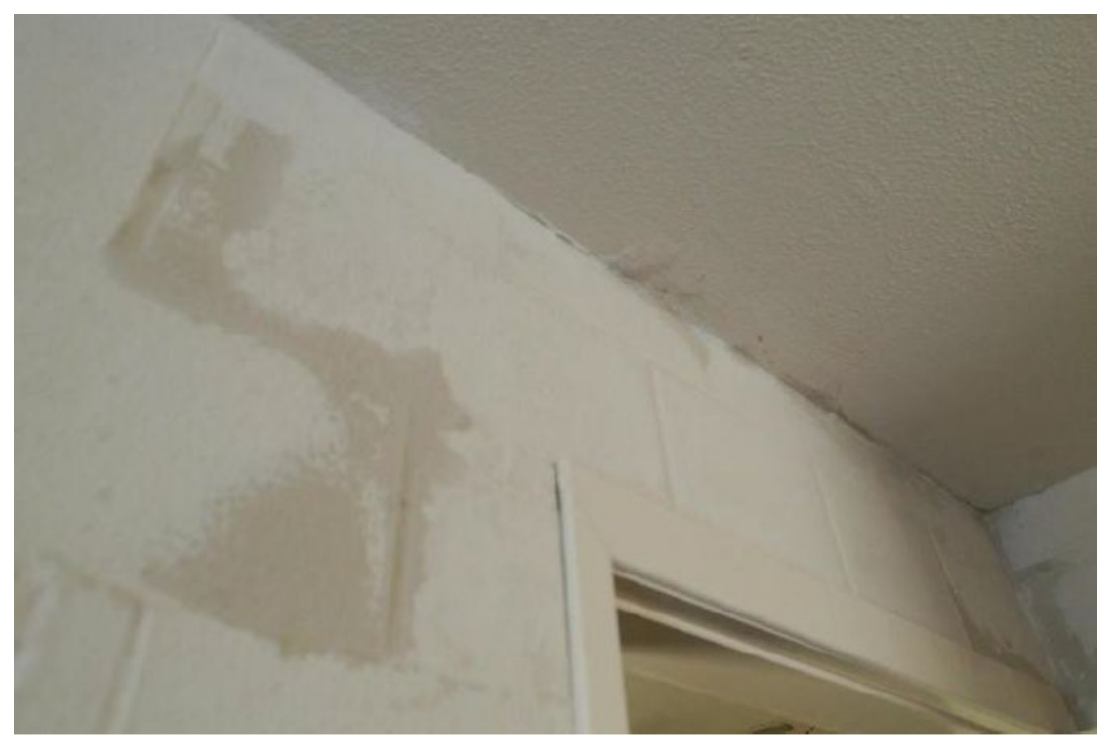

Figura 3. Vazamento da tubulação de água, gerando mancha úmida e extensa na parede (Ramos, 2015).

\subsubsection{Vazamento de calhas}

Segundo Verçoza (1991), são bastante comuns os vazamentos em calhas, condutores e outros aparelhos que são utilizados com a finalidade de se coletar a água de chuvas. Estes vazamentos são manifestados através do escorrimento de água pelas paredes externas, manchas nos forros e lajes, assim como aparecimento de goteiras e mofo (Souza, 2008). Uma das maiores causas dos vazamentos é a falta de manutenção periódica (Figura 4), fazendo com que surjam problemas que poderiam ser evitados como a degradação dos materiais utilizados (oxidação das calhas), furos ou amassamentos nas calhas e condutores e o acúmulo de sujeira entupindo os canais, provocando os vazamentos (Souza, 2008).

Outro tipo de vazamento em calhas e em condutores pode ser causado devido à seção insuficiente, o que representa um erro de projeto. Deste modo, quando chove muito, ocorrerá o transbordo de água. A dificuldade de identificar é o fato de chuvas fortes terem um menor período de retorno, dependendo da região. A solução desse tipo de vazamento será a troca da peça inteira por uma com maior seção, que irá suportar maior quantidade de água (França, Marcondes, et al., 2011). 


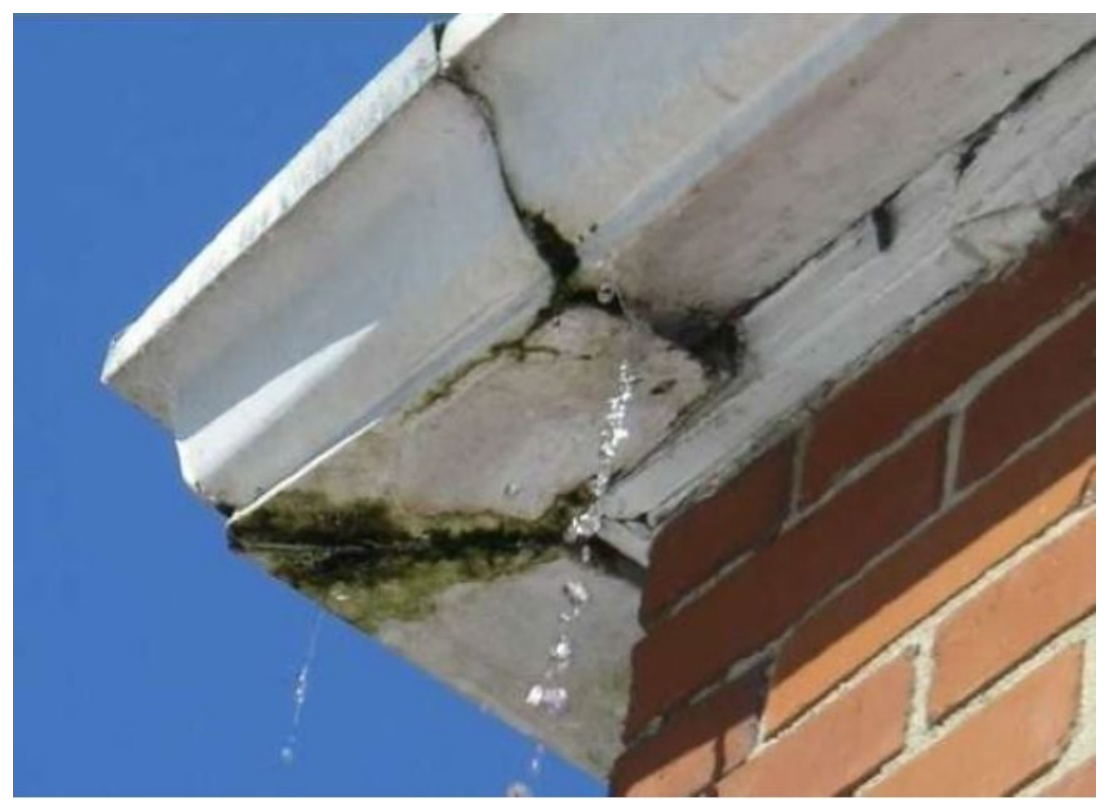

Figura 4. Calha com vazamento em frestas devido a soldas e emendas danificadas, apresentando goteiras e mofo (Tebaldi, 2015).

\subsubsection{Infiltração através da cobertura}

De acordo com Verçoza (1991), a umidade originada por infiltrações nos telhados das edificações normalmente tem como fonte geradora a água da chuva ou defeitos nos barriletes. Segundo Klein (1999), as causas de infiltrações pela cobertura podem estar relacionadas a cada etapa da obra. $\mathrm{Na}$ fase de projeto, os erros podem ser o caimento inadequado para o telhado, o dimensionamento incorreto da estrutura do telhado, a inexistência de um projeto de impermeabilização da laje de cobertura, dimensionamento inadequado para o escoamento das águas pluviais e a não consideração do efeito térmico sobre a laje.

Durante a execução da obra, podemos citar como causas o madeiramento mal executado, fixação inadequada das telhas, sistema de encaixes longitudinais e laterais inadequados, trespasses inadequados, disposição errada das telhas, execução inadequada da impermeabilização, má execução das juntas, rodapés mal executados (arremate inadequado da impermeabilização na platibanda ou muro) (Souza, 2008). Além disso, pode-se incluir como causas de vazamentos a falta de verificação da qualidade das telhas, que podem ser compradas muita finas, empenadas, muito porosas, com tamanhos variáveis e pouco resistentes (Souza, 2008). Outro ponto citado pelo autor é a ausência de manutenção, podendo fazer com que telhas quebradas ou fissuradas, telhas com fungos e mofo, telhas com degradação e telhas fora de posição permitam a entrada de água pluvial. Essa patologia se manifesta em forma de manchas no teto, mofo no teto, desagregação do revestimento, goteiras (Figura 5), apodrecimento do madeiramento, mofo na superfície inferior da telha, eflorescência. 


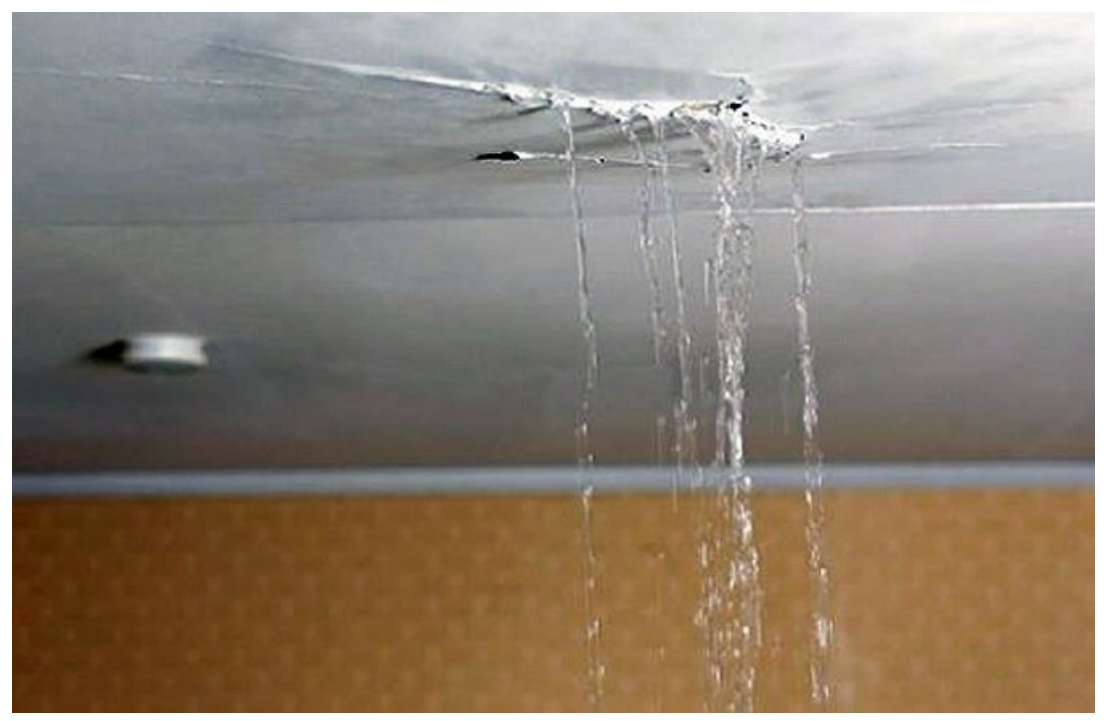

Figura 5. Presença de extensa goteira devido a vazamento de água através da laje danificando a parte interna da edificação (Prado Condomínios, 2016).

\subsubsection{Umidade de infiltração}

Umidade decorrente das águas de chuvas que penetram nas fissuras, trincas ou juntas mal vedadas da fachada (Figura 6) (Kauffeman, 2017). Em caso de parede desprovida de impermeabilização, ao escorrer pela parede a água pode encontrar caminhos para se infiltrar, seja pela gravidade somada à pressão gerada pela ação do vento, ou pela ação da capilaridade em estruturas porosas da alvenaria que absorvem a água (Kauffeman, 2017). As consequências da infiltração da água pelas frestas, mau assentamento das janelas ou trincas é o aparecimento de manchas escuras, que caracterizam a presença de mofo, manchas de umidade, e até destacamento do revestimento no peitoril das janelas.

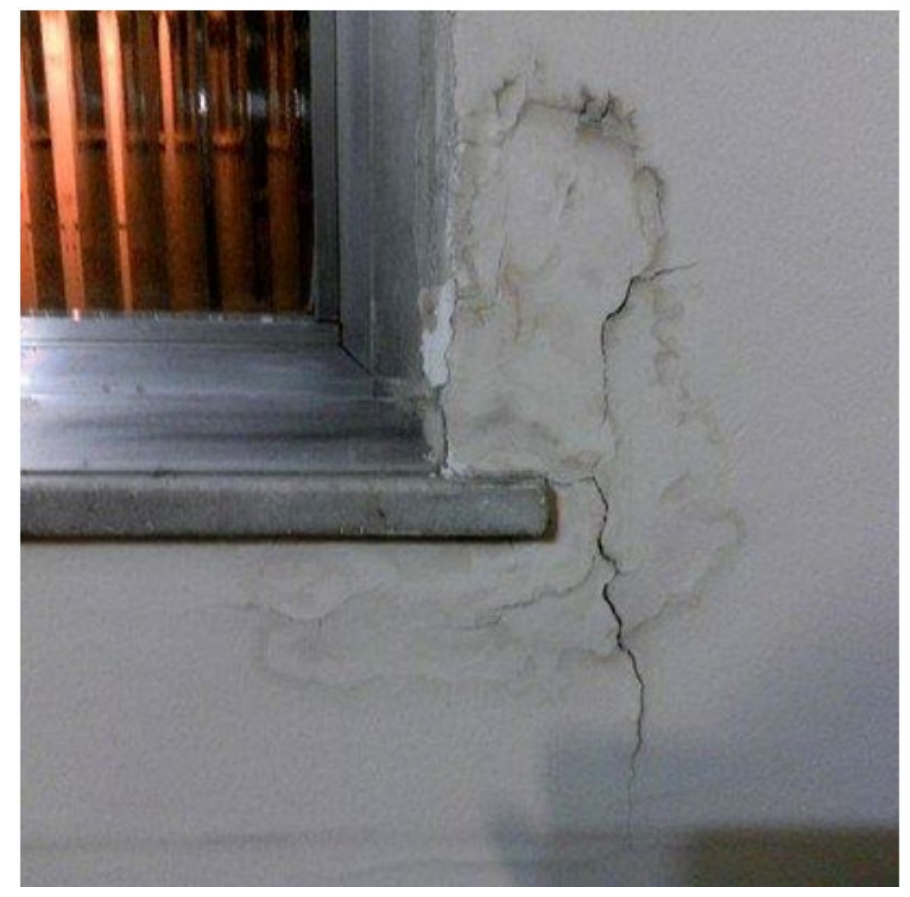

Figura 6. Trincas no peitoril da janela permitindo a infiltração de água na parede interior da edificação (PFLIMPEZA, 2016). 


\subsection{Guia de reparos de infiltrações em edificações}

Foram analisados métodos de correção de patologia causadas pela umidade, e a partir desta análise foi desenvolvido um Guia de Reparos em formato de e-book (Figura 7), que está disponível no link https:/pt.slideshare.net/juliamendes524/guia-de-reparos-das-patologias-de-umidade-emedificaes.

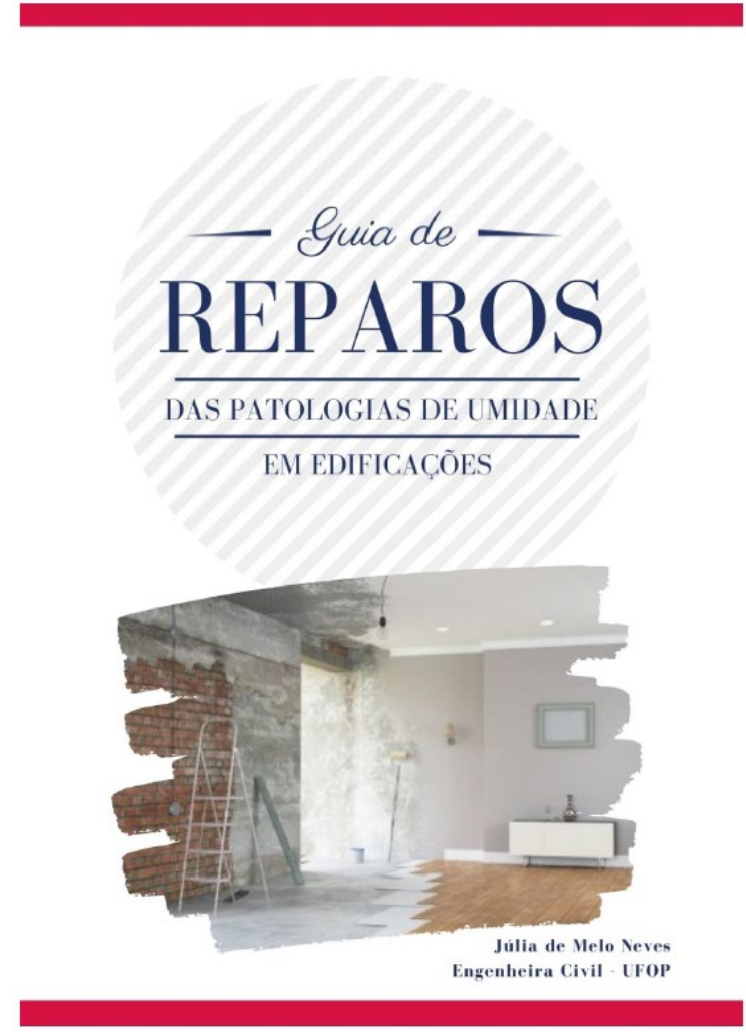

\section{SUMÁRIO}

Figura 7. Capa e sumário do Guia de Reparos de patologia de umidade em edificações elaborado (Fonte: Autora).

O Guia de Reparos possui 40 páginas. O primeiro capítulo explora a reparação causada por umidade acidental proveniente de canos furados ou vazamento de calhas de concreto (Figura 8) ou metálica, além de trazer questões relacionadas à proteção, manutenção e segurança do sistema. $\mathrm{O}$ segundo capítulo exemplifica o tratamento de infiltração através de cobertura, trazendo o passo a passo para reparar a laje e aplicação de impermeabilização com manta asfáltica, manta líquida de base acrílica ou manta líquida de base asfáltica. Esse capítulo também explica como reparar telhados com fita adesiva ou manta asfáltica pré-moldada. O terceiro capítulo expõem sobre a umidade de condensação, trazendo métodos de reparo da esquadria e do teto. Para a umidade de infiltração, exposta no capítulo 4, são tratados reparação de caimento e vedação, trincas e fissuras. Por fim, a umidade ascendente é trazida no último capítulo e aborda os métodos que envolvem a aplicação de argamassa polimérica e impermeabilização da viga baldrame. 


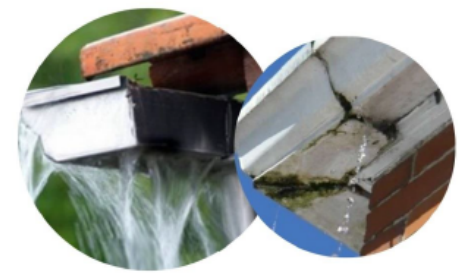

UMIDADE ACIDENTAL

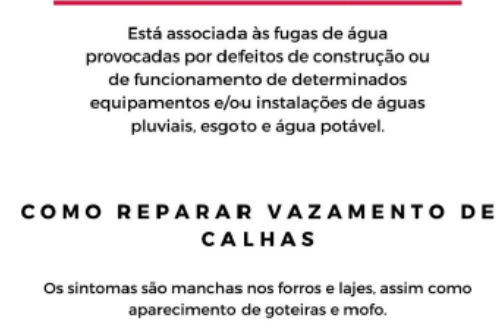

UMIDADE ACIDENTAL

COMOREPARAR VAZAMENTO DE
CALHAS

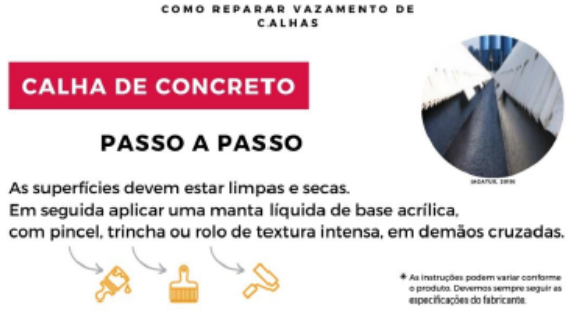

$\longrightarrow$ No caso de reparo de trincas e fissuras pontuais:

Inicialmente para este tratamento as superficies devem estar perfeitamente limpas e secas.

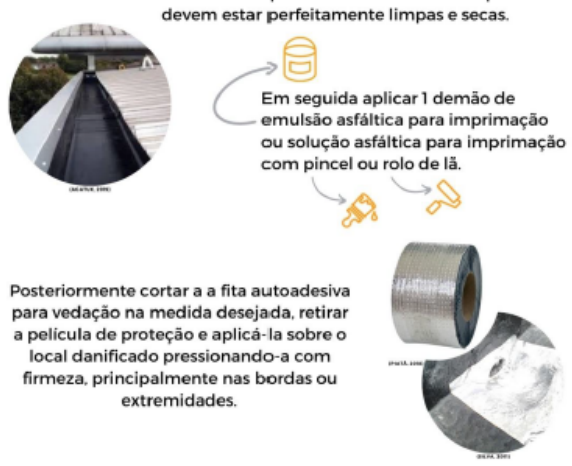

Figura 8. Exemplos de instruções do Guia de Reparos: caso de umidade acidental por vazamento de calha de concreto (Fonte: Autora).

Cabe ressaltar que as especificações e instruções de execução podem variar conforme o fabricante do produto escolhido, portanto devem ser seguidas à risca. Além disso, o acompanhamento de um profissional é indispensável para a qualidade do reparo.

Devido à finalidade de auxiliar a população que sofre com os problemas gerados pela umidade, o guia foi disponibilizado em plataformas online gratuitamente e em entidades de universidades, como Centros Acadêmicos de Engenharia Civil e PET Civil. E a divulgação foi feita através das redes sociais e em eventos da área.

\subsection{Análise crítica}

De acordo com o que foi observado na etapa de revisão bibliográfica, a umidade é a manifestação patológica mais frequentemente observada nas edificações (Peres, 2001). As principais causas da patologia de umidade são as falhas ou ausência de impermeabilização das vigas baldrames, contrapiso e lajes, o mau dimensionamento das esquadrias limitando a ventilação, a má vedação das portas e janelas e a falta de caimento para fora do peitoril, defeitos nas instalações hidrossanitárias e, principalmente, a falta de manutenção preventiva (Ripper \& Souza, 1998). Por isso, este trabalho levantou diversos métodos para reparar esse tipo de patologia, reunindo-os no Guia de Reparos. Porém, tais métodos atuam na manutenção corretiva, o que não seria o ideal. Como já foi explorado, o ideal seria projetar e construir a edificação aplicando as técnicas corretas para que não ocorra essa patologia e trabalhar ao longo da vida útil da edificação com a manutenção preventiva.

Além disso, atualmente, nos deparamos com a falta do pensamento global da edificação por parte dos projetistas. A ausência de compatibilização dos projetos dificulta uma boa execução da obra, 
acarretando incompatibilidade de soluções, imprevistos e improvisos na obra. Essa situação aumenta a probabilidade do surgimento de futura patologia, uma vez que os problemas não são previstos e/ou discutidos na fase do projeto.

Outro fator que reduz a qualidade do desempenho das edificações brasileiras é a prática de economizar ao máximo durante a execução da obra. Raramente os sistemas e materiais de construção são escolhidos com base na sua durabilidade.

As consequências da patologia de umidade afetam diretamente a vida dos usuários das edificações. Estas manifestações patológicas podem provocar desde danos menores a equipamentos e bens presentes nos interiores das edificações, até danos graves como colapsos estruturais, já que água pode intensificar a corrosão da armadura. As manifestações por umidade podem gerar, ainda, desconforto estético devido às manchas escuras, bolhas e descascamento da pintura e tornar o ambiente insalubre, devido à proliferação de fungos.

Esses problemas, entre outros, evidenciam a relevância de um projeto de impermeabilização, que inclua detalhes executivos e uma seleção adequada de produtos. Existem normas detalhadas para a realização destes projetos, porém, no Brasil, o principal problema está relacionado à informalidade no planejamento e execução das obras, atrelado a ausência de fiscalização, criando um cenário propício ao surgimento de patologia.

Quando não se contrata profissionais adequados desde a primeira vez, os projetos se apresentam deficientes, incompletos ou inexistentes, a obra não é executada corretamente e não é elaborado um plano de manutenção periódica. Sem contar que, quando se predomina a manutenção corretiva sem uma visão sistemática da edificação, a patologia poderá ressurgir, agravando a situação e causando prejuízos ainda maiores. Com isso, para que a patologia seja evitada, a realização e a constância das manutenções preventivas são de extrema importância.

Ao analisar o mercado, percebe-se uma predominância de algumas marcas principais e consagradas, nas quais nos baseamos para a realização do presente trabalho. As especificações e funcionalidades que os fabricantes disponibilizam de seus produtos são no geral bem detalhadas, com fotos, descrições, precauções, aplicações e características. Entretanto, apesar de essas marcas disponibilizarem linhas a preços relativamente "acessíveis", a informalidade ainda prevalece. Diversas soluções paliativas e improvisadas estão disponibilizadas de forma disseminada nas redes sociais, a exemplo da mistura de cimento com cola branca para criar um "impermeabilizante caseiro", o que acaba muitas vezes gerando um novo ciclo de problemas ao invés de resolvê-los. Isso acontece porque a população não tem consciência da importância de se usar produtos com garantia de fabricação e falta uma análise de durabilidade e custos a longo prazo.

\section{CONCLUSÕES}

Poucas construções brasileiras possuem um projeto de impermeabilização eficiente, projetos compatibilizados, execução correta, produtos de qualidade e cronograma frequente de manutenção. Portanto, é comum que patologia relacionada à umidade se manifeste afetando diretamente os usuários. Diante disso, a população normalmente adota métodos paliativos para reparar suas edificações e manter padrões mínimos de desempenho e habitabilidade.

Nesse cenário, o presente trabalho consistiu em investigar e selecionar métodos práticos para solucionar patologia existentes e guiar a população para realizar os reparos. Foram abordados os principais tipos de umidade, como a ascendente, de infiltração, acidental e de condensação, e seus respectivos reparos foram agrupados em um Guia de Reparos, disponibilizado gratuitamente. Devido à frequência da patologia de umidade na construção civil brasileira, é de extrema importância esse guia que seja prático, didático, claro e de fácil acesso para a população.

Durante a elaboração do Guia de Reparos, foi notado que o mercado brasileiro possui marcas de

qualidade, que oferecem bons serviços e que dão assistência aos seus consumidores, além de 
fornecer materiais para suporte técnico. Os reparos selecionados para o guia, se executados corretamente com produtos de qualidade, serão relativamente duráveis. Porém, a vida útil dessas medidas pós-obra normalmente não se compara com aquela derivada de um projeto desenvolvido sistemática e holisticamente, compatibilizado e bem executado. Assim, a melhor opção é investir em profissionais qualificados para desenvolver projetos e realizar a execução com qualidade.

Atualmente, existem várias soluções informais disponíveis na internet, que por possuírem um custo inicial menor acabam convencendo o consumidor. Entretanto, o consumidor leigo, por não ter a projeção a longo prazo, não percebe a problemática que isso implica, não só no âmbito financeiro, mas também em relação ao desempenho e durabilidade dos sistemas de sua edificação. Isso é apenas mais um reflexo da realidade do nosso país, onde a informalidade e a autoconstrução são práticas correntes. Este cenário precisa se modificar, pois o ato de construir não deve ser feito sem supervisão profissional, tanto pela segurança quanto pela qualidade das edificações.

Por último, é preciso mudar a cultura sobre manutenção e incentivar investimentos em projetos e execuções de qualidade no Brasil. A população deve compreender a necessidade de se manter o desempenho e segurança de uma edificação, e que a longo prazo só se é possível com as devidas manutenções preventivas. Além disso, cabe ressaltar que quanto mais uma manutenção é adiada, mais cara ela se torna a longo prazo. Por isso, a mudança de mentalidade da população é fundamental para tornar essa cultura de manutenções preventivas mais presentes nas edificações brasileiras.

\section{AGRADECIMIENTOS}

Os autores agradecem à UFOP e UFJF pelo apoio para a realização e apresentação dessa pesquisa.

\section{REFERÊNCIAS}

ABNT. (2013). NBR 15575: Desempenho de edificações habitacionais. Rio de Janeiro.

Bauermann, C. (2018). Patologias provocadas por umidade em edificações. Trabalho de Conclusão de Curso, Anápolis. Acesso em 3 de Julho de 2019, disponível em https://repositorio.pgsskroton.com.br/bitstream/123456789/23086/1/2\%20CRISTIANO\% 20VIEIRA\%20BAUERMANN\%20-\%20TCC.pdf

Brucke. (2018). Dica de como se prevenir da umidade no inverno. Acesso em 23 de Junho de 2019, disponível em Brucke: https://www.brucke.com.br/dica-de-como-se-prevenir-da-umidadeno-inverno/

França, Marcondes, et al. (Setembro de 2011). Patologia das construções: uma especialidade na engenharia civil. Téchne, 174. Acesso em 3 de Julho de 2019, disponível em http://techne17.pini.com.br/engenharia-civil/174/patologia-das-construcoes-umaespecialidade-na-engenharia-civil-285892-1.aspx

Garrafoli, N. (2010). Qualidade na construção civil . Acesso em 15 de Junho de 2019, disponível em Portal VGV: https://www.portalvgv.com.br/site/qualidade-na-construcao-civil-pornatal-jose-garrafoli

Kauffeman, R. (2017). Manifestações patológicas: análise e tratamento de combate a infiltrações por capilaridade em edificações. Trabalho de Conclusão de Curso, Centro Universitário Anhanguera, Leme. 
Klein, D. (1999). Apostila do Curso de Patologia das Construções. $10^{\circ}$ Congresso Brasileiro de Avaliações e Perícias. Porto Alegre.

Martins, P. (2019). Estudo dos principais desafios do desempenho térmico das edificações no Brasil. Trabalho de Conclusão de Curso, Universidade Federal de Ouro Preto, Ouro Preto.

Nakamura, J. (2018). Programa de manutenção preventiva garante vida longa aos edifícios. Acesso em 15 de Junho de 2019, disponível em Arquitetura, Construção e Engenharia : https://www.aecweb.com.br/cont/m/rev/programa-de-manutencao-preventiva-garantevida-longa-aos-edificios_17916_10_0

Oliveira, V. S. (2017). Análise e tratamento das manifestações patólogicas causadas por infiltração em edificações. Trabalho de Conclusão de Curso , Faculdade Pitágoras, Londrina.

Peres, R. (2001). Levantamento e identificação de manifestações patológicas em prédio histórico: um estudo de caso. Dissertação de Mestrado, Universidade Federal do Rio Grande do Sul, Porto Alegre.

Perez, A. (1985). Umidade nas Edificações: recomendações para a prevenção de penetração de água pelas fachadas. São Paulo: 1985.

PFLIMPEZA. (2016). Telhado com bolor e mofo. Acesso em 3 de Julho de 2019, disponível em Habitíssimo: https://fotos.habitissimo.com.br/foto/telhado-com-bolor-e-mofo_698922

Prado Condomínios . (2016). Infiltração com origem no meu terraço. Acesso em 4 de Julho de 2019, disponível em Prado Condomínios: https://www.pradocondominios.com/infiltracaocom-origem-no-meu-terraco-o-que-fazer/

Ramos , F. (2015). Como identificar uma infiltração . Acesso em 28 de Novembro de 2019, disponível em GaúuchaZh: https://gauchazh.clicrbs.com.br/economia/mercadoimobiliario/noticia/2015/04/como-identificar-uma-infiltracao-4740577.html

Rendelucci, F. (2005). Capilaridade - A passagem natural do líquido por um tubo muito fino. Acesso em 03 de Julho de 2015, disponível em Educação UOL: https://educacao.uol.com.br/disciplinas/quimica/capilaridade-a-passagem-natural-doliquido-por-um-tubo-muito-fino.htm

Ripper, T., \& Souza, C. (1998). Patologia, recuperação e reforço de estruturas de concreto. São Paulo: PINI.

Santos, Ribeiro, et al. (2012/2013). A Humidade na Construção - Formas, causas e prevenção. Acesso em 03 de Julho de 2019, disponível em https://paginas.fe.up.pt/ projfeup/cd_2012_13/files/REL_12MC06_01.PDF

Souza, M. (2008). Patologias ocasionadas pela umidade nas edificações. Trabalho de Conclusão de Curso , Universidade Federal de Minas Gerais, Belo Horizonte .

Tebaldi, R. (2015). Sinais que você precisa de calhas novas. Acesso em 3 de Julho de 2019, disponível em Vai com tudo: https://www.vaicomtudo.com/6-sinais-que-voce-precisa-decalhas-novas.html 
Tintas e Pintura. (2017). Humidade por Condensação - Causas e Soluções. Acesso em 25 de Junho de 2019, disponível em Tintas e Pintura: https://www.tintasepintura.pt/humidade-porcondensacao-causas-e-solucoes/

Verçosa, E. (1991). Patologia das Edificações. Porto Alegre: Sagra.

Yazigi, W. (2009). A Técnica de Edificar (10ª ed.). São Paulo: PINI. 